\title{
Inhibition of Histamine H1 Receptor Activity Modulates Proinflammatory Cytokine Production of Dendritic Cells through c-Rel Activity
}

\author{
Chin-Lai Lee $^{a}$ Shih-Hsien Hsu ${ }^{a} \quad$ Yuh-Jyh Jong ${ }^{a, b, d} \quad$ Chih-Hsing Hunga, b, d, e \\ Jau-Ling Suen ${ }^{a, c}$ \\ ${ }^{a}$ Graduate Institute of Medicine, ${ }^{b}$ Department of Pediatrics, Faculty of Pediatrics, and ${ }^{\mathrm{c}}$ Department of \\ Microbiology, Faculty of Medicine, College of Medicine, Kaohsiung Medical University, dDepartment of Pediatrics, \\ Kaohsiung Medical University Hospital, and ${ }^{\text {}}$ Department of Pediatrics, Kaohsiung Municipal Ta-Tung Hospital, \\ Kaohsiung, Taiwan, ROC
}

\section{Key Words}

c-Rel · Dendritic cells · Histamine $\mathrm{H} 1$ receptor - Tumor necrosis factor- $\alpha$

\begin{abstract}
Background: Histamine exerts diverse effects on immune regulation through four types of histamine receptors (HRs). Among them, type 1 receptor (H1R) plays an important role in allergic inflammation. Dendritic cells (DCs), which express at least three types of HRs, are professional antigen-presenting cells controlling the development of allergic inflammation. However, the molecular mechanisms involved in H1Rmediated NF- $\mathrm{KB}$ signaling of DCs remain poorly defined. Methods: Bone-marrow (BM)-derived DCs (BM-DCs) were treated with $\mathrm{H} 1 \mathrm{R}$ inverse agonists to interrupt basal H1R-mediated signaling. The crosstalk of H1R-mediated signaling and the NF- $\mathrm{KB}$ pathway was examined by NF- $\mathrm{KB}$ cellular activity using a luciferase reporter assay, NF- $\mathrm{KB}$ subunit analysis using Western blotting and TNF- $\alpha$ promoter activity using chromatin immunoprecipitation. Results: Blockage of H1R signaling by inverse agonists significantly inhibited TNF- $\alpha$ and IL- 6 production of BM-DCs. H1R-specific agonists were able to enhance TNF- $\alpha$ production, but this overexpression was significantly inhibited by NF-кB inhibitor. The
\end{abstract}

H1R inverse agonist ketotifen also suppressed cellular NFactivity, suggesting crosstalk between $\mathrm{H} 1 \mathrm{R}$ and NF-кB signaling in DCs. After comprehensive analysis of NF-KB subunits, c-Rel protein expression was significantly down-regulated in ketotifen-treated BM-DCs, which led to inhibition of the promoter activity of TNF- $\alpha$. Finally, adoptive transfer of the ketotifen-treated BM-DCs did not induce significant allergic airway inflammation compared to that of control cells in vivo. Conclusions: Our results suggest that c-Rel controls H1R-mediated proinflammatory cytokine production in DCs. This study provides a potential mechanism of H1R-mediated signaling and NF- $\mathrm{KB}$ pathway crosstalk in allergic inflammation.

Copyright $\odot 2012$ S. Karger AG, Basel

\section{Introduction}

Histamine exerts diverse effects on many physiological and pathological conditions through four different types of histamine receptors (HRs) - H1R, H2R, H3R and H4R [1]. Each HR is characterized by a specific expression

\section{C.-L.L. and S.-H.H. contributed equally to this study.}

\section{KARGER}

Fax +41613061234

E-Mail karger@karger.ch

www.karger.com
(C) 2012 S. Karger AG, Basel

$1018-2438 / 13 / 1603-0265 \$ 38.00 / 0$

Accessible online at:

www.karger.com/iaa
Correspondence to: Dr. Jau-Ling Suen or Dr. Chih-Hsing Hung

Graduate Institute of Medicine, College of Medicine, Kaohsiung Medical University 100, Shih-Chuan 1st Road

Kaohsiung 80708, Taiwan (ROC)

Tel. +886 7312 1101, E-Mail jlsuen@kmu.edu.tw, chhung@kmu.edu.tw 
pattern and function. H1R and H2R are ubiquitously expressed on lymphoid and nonlymphoid cells, while H3R [2] and H4R [3, 4] are expressed by a majority of cells in the nervous system and on hematopoietic cells, respectively. Histamine primarily mediates acute and chronic allergic inflammation through H1R [5]. H1R, as well as other HRs, belongs to the G-protein-coupled receptor family. The H1R-mediated signaling pathway has been well studied in model cell line systems. H1R activates phospholipase $C$ through pertussis toxin-resistant $G_{q / 11}$ proteins [6]. Phospholipase $C$ then catalyzes phosphatidylinositol-4,5-bisphosphate from the membrane into $\mathrm{IP}_{3}$ (inositol-1,4,5-trisphosphate) and diacylglycerol. $\mathrm{IP}_{3}$ releases $\mathrm{Ca}^{2+}$ from intracellular calcium stores and initiates the $\mathrm{Ca}^{2+}$-dependent pathway, whereas diacylglycerol activates protein kinase C. A previous study suggested that histamine-activated protein kinase $\mathrm{C}$ isoforms are associated with the activation of Raf/MEK/ERK and $\mathrm{IKK} / \mathrm{I} \kappa \mathrm{B} / \mathrm{NF}-\kappa \mathrm{B}$ cascades in the up-regulation of cytokine expression of keratinocytes [7]. Crosstalk between H1R-mediated signaling and the NF-кB pathway may regulate cytokine production of immune cells. However, the mechanisms underlying this crosstalk in immune cells, especially dendritic cells (DCs), have not been fully elucidated.

DCs control T-cell activation and differentiation by cytokines and/or ligands [8]. Originating from bonemarrow (BM)-derived precursors, DCs migrate to the periphery in an immature state with high phagocytic but low T-cell-stimulatory activity. Upon stimulation, DCs migrate to local lymph nodes and differentiate into cells with mature phenotype with high T-cell-stimulatory but low phagocytic activity $[9,10]$. DCs also secrete several proinflammatory cytokines, such as TNF- $\alpha$ and IL-6, in order to regulate inflammation. These $\mathrm{DC}$ functions are primarily mediated by the NF- $\kappa \mathrm{B}$ pathway. NF- $\kappa \mathrm{B}$ family members include RelA (p65), NF- $\kappa$ B1 (p50; p105), NF$\kappa B 2$ (p52; p100), RelB and c-Rel. Distinct NF- $\mathrm{B}$ subunit composition affects DC development and function [11]. The results of the studies using NF- $\kappa$ B subunit knockout mice indicate that c-Rel and p50 control the genes important for T-cell responses induced by lipopolysaccharide (LPS)-stimulated BM-DCs (CD40, IL-12p40 and IL-18), but not the genes for encoding proinflammatory cytokines (TNF- $\alpha$, IL- $1 \alpha$ and IL-6). In contrast, the RelA subunit regulates genes encoding proinflammatory cytokines but not the genes for T-cell responses [12]. Thus, $\mathrm{NF}-\kappa \mathrm{B}$ is an important regulator of T-cell responses and proinflammatory activity of DCs [13].
Histamine can influence DCs to determine the types of inflammation produced by its interaction with different HRs, as these cells can express H1R, H2R and H4R $[14,15]$. It has been demonstrated that histamine inhibits IL-12 production but enhances IL-10 and IL- 6 expression of DCs [15]. Histamine-treated DCs drive T-helper 2 (Th2) polarization in both human and mouse DCs, which may be mediated by H1R and H4R $[4,15,16]$. These studies imply that histamine can regulate immune responses by affecting the maturation of DCs and altering their T-cell-polarizing capacity $[16,17]$. It also has been demonstrated that DCs can actively synthesize histamine during the differentiation period and that blocking histamine synthesis disturbs DC differentiation [18]. Consequently, the interaction of histamine with different HRs expressed by DCs affects the differentiation and effector functions of these cells.

As each HR has a different pattern of cellular expression, affinity for histamine and specifics of signaling transduction, the effects of histamine on DCs are rather complex. In order to study the molecules involved in the histamine-H1R axis of DCs, we utilized H1R inverse agonists to block H1R-mediated signaling in BM-DCs without exogenous histamine. It has been demonstrated that granulocyte-macrophage colony-stimulating factor (GM-CSF)-differentiated BM-DCs can produce histamine and secrete it after synthesis [18]. Given that H1R consists of an inactive form and an active form, the inactive state of H1R can be in equilibrium with the active form in an agonist-dependent or independent manner [5]. Also, an inverse agonist preferentially binds the inactive form of H1R and finally causes a shift in the equilibrium toward the inactive state, which is characterized by blocked signaling via H1R [19].

Here, we demonstrate that inhibition of basal H1R activity of BM-DCs by H1R inverse agonists significantly decreases proinflammatory cytokine production, especially that of TNF- $\alpha$ and IL-6. Blockage of H1R-mediated signaling of BM-DCs decreased their ability to induce allergic airway responses in vivo. We also provide evidence that c-Rel directly binds to TNF- $\alpha$ promoter and controls its activity in H1R-mediated signaling.

\section{Material and Methods}

Mice

$\mathrm{BALB} / \mathrm{c}$ were obtained from the National Taiwan University and maintained by the Animal Center of the Kaohsiung Medical University in a pathogen-free environment. Female BALB/c mice, 6-8 weeks of age, were used as the source of BM-DCs. All animal 
Table 1. Cytokine production by BM-DCs

\begin{tabular}{lccccccc}
\hline & \multicolumn{2}{l}{ Day 4 BM-DCs } & & \multicolumn{2}{l}{ Day 6 BM-DCs } \\
\cline { 2 - 4 } \cline { 6 - 8 } & - & LPS & poly I:C & & - & LPS & poly I:C \\
\hline TNF- $\alpha$ & $4,903 \pm 1,739$ & $5,037 \pm 884$ & $2,854 \pm 1,005$ & & $2,125 \pm 104$ & $5,448 \pm 843^{*}$ & $4,598 \pm 980^{*}$ \\
IL-6 & $635 \pm 121$ & $4,750 \pm 1,216^{*}$ & $1,233 \pm 422$ & & $1,584 \pm 587$ & $10,110 \pm 3,915^{*}$ & $6,927 \pm 2,780^{*}$ \\
IL-10 & $9 \pm 4$ & $54 \pm 9^{*}$ & $56 \pm 7^{*}$ & & $10 \pm 3$ & $48 \pm 10^{*}$ & $65 \pm 18^{*}$ \\
IL-12 & $15 \pm 4$ & $25 \pm 4$ & $13 \pm 4$ & & $10 \pm 6$ & $22 \pm 4$ & $15 \pm 3$ \\
\hline
\end{tabular}

Purified CD11c+ BM-DCs were treated with or without LPS $(10 \mathrm{ng} / \mathrm{ml})$ or poly I:C (10 $\mu \mathrm{g} / \mathrm{ml})$ for $24 \mathrm{~h}$. Cytokine levels in the culture supernatant were assessed by multiplex immunoassay. Data represent means $\pm \mathrm{SD}$ (pg/ml) of 3 experiments. ${ }^{*} \mathrm{p}<0.05$ vs. vehicle-treated cells (Mann-Whitney U test).

experiments were performed according to the guidelines of the Institutional Animal Care and Use Committee of the Kaohsiung Medical University.

\section{Generation from BM Cultures}

BM-DCs were prepared as described previously [20, 21]. Briefly, BM cells were placed in 24-well plates in $1 \mathrm{ml}$ of medium supplemented with recombinant murine GM-CSF $(500 \mathrm{U} / \mathrm{ml})$ and IL-4 (1,000 U/ml; PrePro Tech, Rocky Hill, N.J., USA) for 4 or 6 days. Every other day, fresh medium containing GM-CSF and IL- 4 was added. The phenotype and purity of BM-DCs were analyzed by flow cytometry (LSR II; BD Biosciences, San Diego, Calif., USA), examining the expression of CD11c (HL3), IA ${ }^{\mathrm{d}}$ (AMS32.1), CD40 (1C10), CD80 (16-10A1) and CD86 (GL1). Day-4 or -6 cells were further purified with anti-mouse CD11c magnetic beads (Miltenyi Biotec, Sunnyvale, Calif., USA) according to the manufacturer's instructions.

\section{Cell Treatment}

The purified BM-DCs (purity $>95 \%$ ) were treated with different concentrations of H1R inverse agonists (ketotifen or cyproheptadine), selective HR agonists [2-pyridylethylamine dihydrochloride (2-PEA) for H1R, dimaprit for H2R, (R)- $\alpha$-methylhistamine for H3R, 4-methylhistamine for H4R; all from Tocris Bioscience, Missouri, Mo., USA] or BAY7085 with or without LPS (10 ng/ml, Escherichia coli O127:B8; Sigma-Aldrich, St. Louis, Mo., USA) or polyinosinic-polycytidylic acid (poly I:C; $10 \mu \mathrm{g} / \mathrm{ml}$; Sigma-Aldrich) for $24 \mathrm{~h}$. The viability of $80 \mu \mathrm{M}$ inverse-agonist- or selective-agonist-treated BM-DCs was similar to that of control cells using 7-AAD staining. The supernatant was collected for cytokine or histamine (Immuno-Biological Laboratories, Minneapolis, Minn., USA) determination and cells were harvested for phenotypic analysis.

\section{Cytokine Determination}

Multiple cytokines (table 1) in the culture supernatant were simultaneously determined with a cytometric bead array kit (BD Biosciences), which contains microparticles that are dyed to different fluorescence intensities of approximately $650 \mathrm{~nm}$. The experimental procedure was modified as described previously [22]. The samples were then run on a FACSarray flow cytometer (BD Biosciences) and analyzed using cytometric bead array software
(BD Biosciences). Cytokine levels in some experiments were assayed by ELISA (R\&D Systems, Minneapolis, Minn., USA).

\section{Western Blotting}

The treated BM-DCs were lysed in the sample buffer [3\% SDS (sodium dodecyl sulfate), $1.67 \mathrm{M}$ urea and $2.7 \% \beta$-mercaptoethanol), resolved in a $10 \%$ SDS-polyacrylamide gel and electrotransferred onto Hybond-C extra membranes (Amersham, Piscataway, N.J., USA). The blots were blocked with TBST (50 mM Tris- $\mathrm{HCl}$, $0.15 \mathrm{M} \mathrm{NaCl}$ and $0.05 \%$ Tween 20 ) containing $2.5 \%$ non-fat milk at room temperature for $1 \mathrm{~h}$ and then incubated with primary antibodies at $4^{\circ} \mathrm{C}$ overnight. Bound antibodies were detected with peroxidase-labeled secondary antibodies at room temperature for $2 \mathrm{~h}$, and blots were developed by Western Lightning chemiluminescence reagent (Perkin Elmer, Waltham, Mass., USA). Blots were washed with TBST four times in between steps. The primary antibodies used in this experiment included anti-c-Rel, antiRelB, anti-p65 (all from Santa Cruz Biotechnology, Santa Cruz, Calif., USA), anti-pp65 (Abcam, Cambridge, Mass., USA), anti$\beta$-actin, anti-p52 and anti-p100 (all from Millipore, Billerica, Mass., USA), anti-p50 and anti-p105 (all from eBioscience, Hatfield, UK).

\section{Chromatin Immunoprecipitation Assay}

The treated BM-DCs were fixed with $1 \%$ formaldehyde at $37^{\circ} \mathrm{C}$ for $10 \mathrm{~min}$, washed with phosphate-buffered saline and then lysed in a lysis buffer (1\% SDS, $10 \mathrm{mM}$ EDTA and $50 \mathrm{~mm}$ Tris-HCl with protease inhibitors). The lysed cells were sonicated and incubated with an anti-c-Rel antibody (Santa Cruz Biotechnology) at $4^{\circ} \mathrm{C}$ overnight, followed by addition of protein-G agarose beads (Millipore) for further $1 \mathrm{~h}$. The beads were then sequentially washed with low- and high-salt buffer, $\mathrm{LiCl}$ washing buffer and TE buffer. The immunoprecipitated complexes were eluted with elution buffer, treated with $5 \mathrm{M} \mathrm{NaCl}$ at $65^{\circ} \mathrm{C}$ for $4 \mathrm{~h}$ and digested with proteinase $\mathrm{K}$. The released DNA fragments were purified using a DNA purification kit (Favorgen, Ping-Tung, Taiwan, ROC) according to manufacturer's instructions and then subjected to realtime PCR detection of the TNF- $\alpha$ promoter. Genomic DNA was used as a positive control. The following primer sets for the detection of the NF- $\kappa$ B binding site in TNF- $\alpha$ promoter were used: forward, AAGGAGAAGGCTTGTGAGGTC, and reverse, TCTGAAAGCTGGGTGCATAAG. 
Luciferase Reporter Assay

The two reporter constructs, pRL-SV40 (Renilla luciferase; Promega, Madison, Wisc., USA) and pNF- $\kappa$ BLuc or control vector (firefly luciferase; Promega), were co-transfected into $1 \times 10^{6}$ THP-1 cells. After a 16-hour treatment, the washed cells were then treated with various concentrations of ketotifen for another $8 \mathrm{~h}$. Luciferase activity was then measured with the dual luciferase kit (Promega). Relativeluciferaseactivitywasdefined asfirefly/Renilla ratio normalized to control vector transfection.

Adoptive Transfer of BM-DCs and Assessment of Allergic

Lung Inflammation

Purified day-4 BM-DCs treated with or without ketotifen $(80$ $\mu \mathrm{M})$ were cultured with ovalbumin (OVA; $200 \mu \mathrm{g} / \mathrm{ml}$; grade V; Sigma-Aldrich) for $24 \mathrm{~h}$ and instilled intravenously $\left(2 \times 10^{5}\right.$ cells/ recipient) into syngeneic naïve mice. After 1 week, mice were subjected to 15 -min daily exposure with OVA $(3 \% \mathrm{w} / \mathrm{v}$ in phosphatebuffered saline) on 4 consecutive days. Twenty-four hours after the last OVA challenge, mice were sacrificed and bronchoalveolar lavage fluid (BALF) was obtained as described previously [23]. Cells in BALF were stained with PE-Cy7-anti-CD11c (N418; eBioscience) and FITC-anti-I-A ${ }^{\mathrm{d}} / \mathrm{I}-\mathrm{E}^{\mathrm{d}}$ (M5/114.15.2; eBioscience; DCs/ macrophages), PE-anti-CCR3 (83101; R\&D Systems; eosinophils), APC-anti-CD3 (145-2C11; BD Biosciences) and anti-B220 (RA36B2; eBioscience; lymphocytes). The cellular composition of BALF cells was determined by flow cytometry (LSR II; BD Biosciences).

\section{Statistical Analysis}

Statistical comparisons of data among groups of control and treated BM-DCs were performed with the nonparametric MannWhitney $U$ test. Values of $p<0.05$ were considered significant. All statistical tests were performed by SPSS for Windows, version 13.0. (SPSS Inc., Chicago, Ill., USA).

\section{Results}

Significant Suppression of Proinflammatory Cytokine Production of BM-DCs by H1R Inverse Agonists

We used a well-defined culture system for GM-CSFmediated generation of DCs from BM cells. BM precursors from $\mathrm{BALB} / \mathrm{c}$ mice were incubated with GM-CSF and IL- 4 for 4 or 6 days, which represented different stages of maturation of BM-DCs [20]. Cytokine assessment showed that either day- 4 or -6 BM-DCs constitutively secreted TNF- $\alpha$ and IL-6, but not IL-10 and IL-12 (table 1), whereas both LPS and poly I:C significantly enhanced the expression of TNF- $\alpha$, IL- 6 and IL-10 from day- 6 BMDCs. In contrast to day- 6 BM-DCs, day-4 BM-DCs seemed more 'insensitive' to stimuli, because LPS and poly I:C did not enhance their TNF- $\alpha$ production and poly I:C did not affect the level of IL- 6 from day-4 BMDCs either. The possible reason may be the strength of Toll-like receptor (TLR) 4 signaling. At the dose of $0.5 \mu \mathrm{g} /$ $\mathrm{ml}$ of LPS (instead of $10 \mathrm{ng} / \mathrm{ml}$ ), both day- 4 and $-6 \mathrm{BM}$ -
DCs secreted significantly more TNF- $\alpha$ and IL-12 than corresponding unstimulated controls (data not shown).

Due to endogenous histamine synthesis of BM-DCs [18], BM-DCs have constitutive H1R-mediated activity. Thus, in order to examine the role of H1R-mediated signaling in DC activity, inverse agonists of H1R were used to treat BM-DCs in the absence of histamine to inhibit the constitutive H1R-mediated downstream signaling. Ketotifen and cyproheptadine are inverse agonists for $\mathrm{H} 1 \mathrm{R}$ and are clinically used as prophylactic agents in the treatment of allergic reactions [24-26]. As shown in figure 1, ketotifen significantly inhibited TNF- $\alpha$ and IL- 6 production from day- 4 and -6 BM-DCs in a dose-dependent manner. Notably, $100 \mu \mathrm{M}$ of ketotifen almost suppressed all TNF- $\alpha$ production from day- 4 BM-DCs and around 50\% from day- 6 BM-DCs. Regarding IL-6, ketotifen had a similar effect on day- 4 and -6 BM-DCs, although the degree of inhibition of IL-6 (fig. 1c, d) was not as dramatic as that seen for TNF- $\alpha$ (fig. 1a, b). Treatment with another H1R inverse agonist, cyproheptadine, resulted in day-4 BM-DCs in a similar inhibition. Consequently, blocking H1R-mediated signaling may mediate the inhibition of TNF- $\alpha$ and IL- 6 expression of BM-DCs.

To re-confirm the suppressive effect of ketotifen on DCs, we also used GM-CSF-derived BM-DCs (without IL-4 in the culture), another well-defined culture system for DC differentiation [27]. Ketotifen also significantly inhibited TNF- $\alpha$ and IL- 6 production from BM-DCs (data not shown). These data indicate that the constitutive H1R-mediated activity of BM-DCs is associated with their basal expression of proinflammatory cytokines, especially TNF- $\alpha$.

Specific Involvement of H1R-Mediated Signaling in

Proinflammatory Cytokine Production of BM-DCs

Given that BM-DCs differentiated with GM-CSF can produce and release histamine $[18,28]$, we determined histamine release by ketotifen-treated BM-DCs. As shown in figure $2 \mathrm{a}$, under resting conditions BM-DCs secreted histamine in a time-dependent manner. After 24hour treatment, ketotifen significantly inhibited histamine release by BM-DCs. In order to rule out the possibility that an autocrine loop of histamine release can act on other HRs to stimulate proinflammatory cytokine production, selective agonists for $\mathrm{H} 2 \mathrm{R}$ (dimaprit), H3R (R- $\alpha$-methylhistamine) and H4R (4-methylhistamine) were used to treated BM-DCs for $24 \mathrm{~h}$. As shown in figure $2 \mathrm{~b}$, none of these agonists affected TNF- $\alpha$ and IL- 6 (data not shown) expression by BM-DCs, suggesting that H1Rmediated signaling is specifically involved in proinflammatory cytokine production of BM-DCs. 


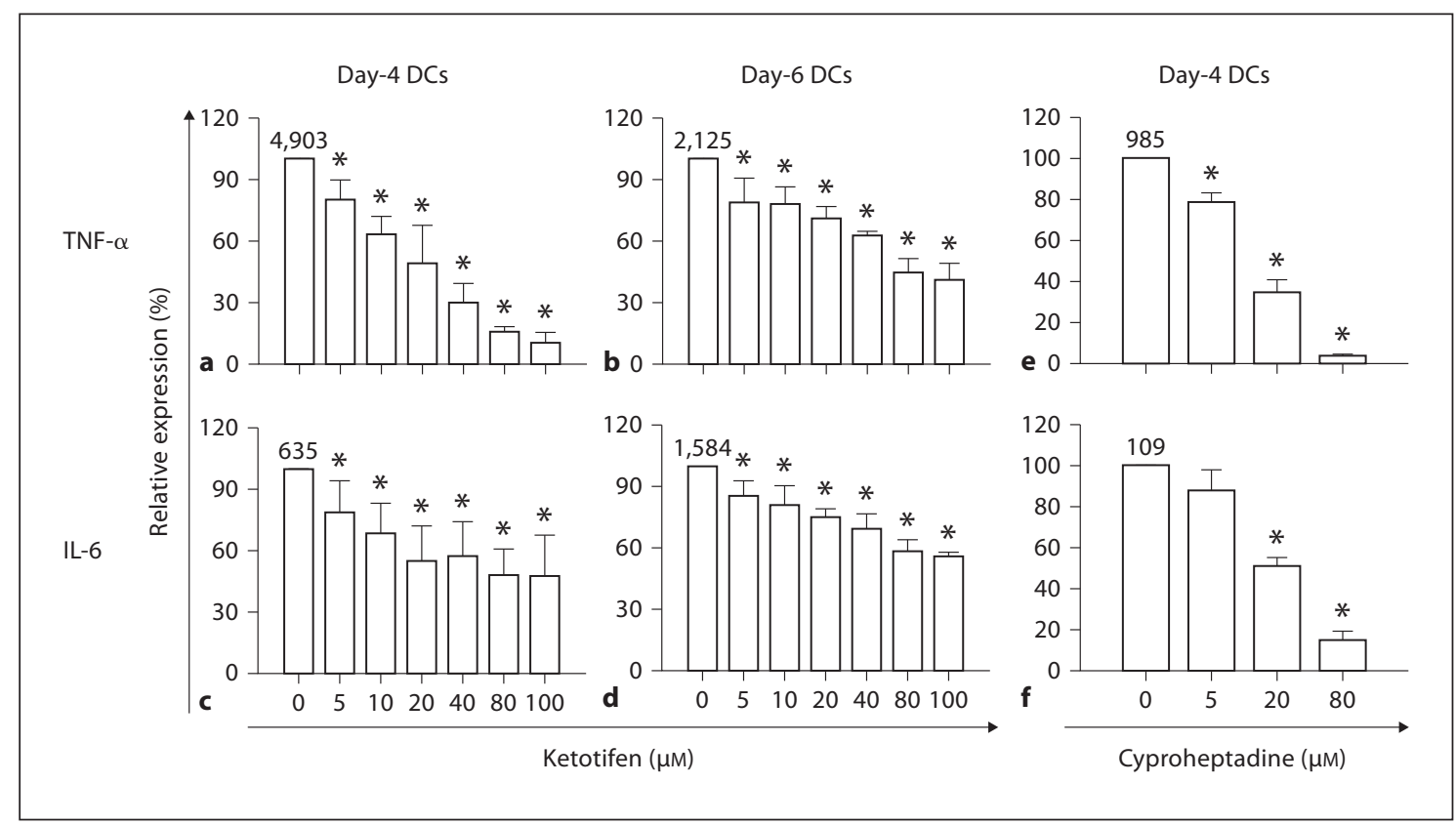

Fig. 1. H1R inverse agonists inhibited spontaneous TNF- $\alpha$ and IL- 6 production by BM-DCs. Purified day- 4 (a, c, e, f) or day- 6 CD11c+ BM-DCs (b, d) were treated with ketotifen or cyproheptadine at increasing concentrations without any stimuli for $24 \mathrm{~h}$. The levels of cytokines in the culture supernatants were measured by multiplex immunoassay (a-d) or ELISA (e-f). Results are shown as relative expression (\%) compared to control (BM-DCs only; mean \pm SD of 3 experiments). ${ }^{*} \mathrm{p}<0.05$ vs. BM-DCs only. The number in each graph represents the cytokine level (pg/ml) of vehicle-treated BM-DCs.

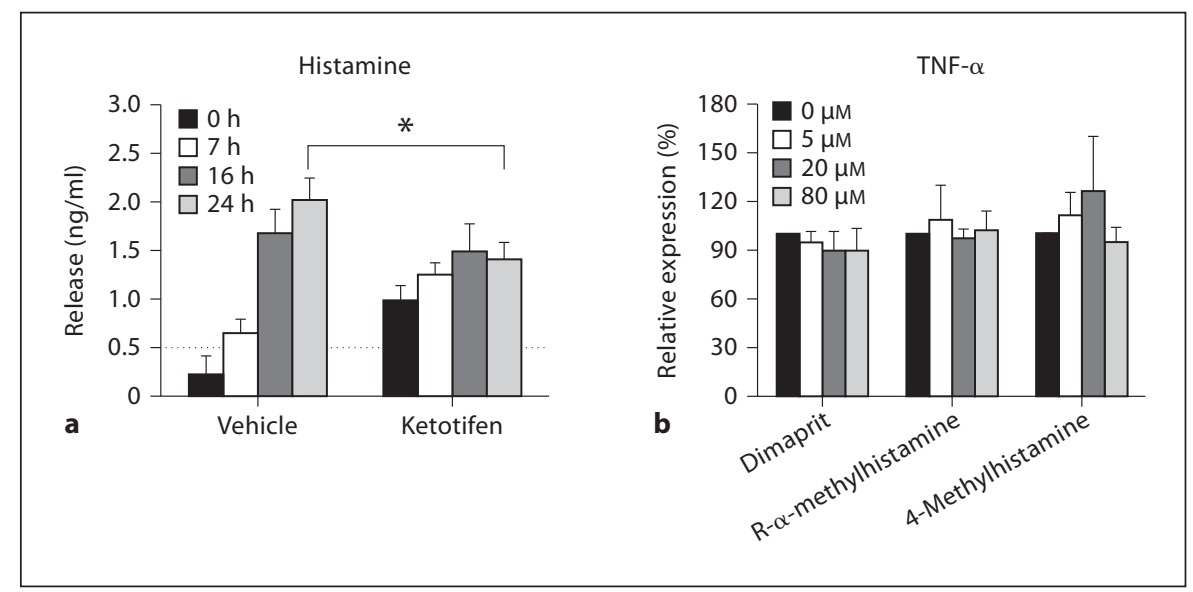

Fig. 2. H2R-, H3R- or H4R-mediated signaling did not affect TNF- $\alpha$ expression by BM-DCs. a Purified day- 4 BM-DCs were washed, suspended at a concentration of $6 \times 10^{5} / \mathrm{ml}$ and treated with ketotifen for different periods. The level of histamine in the supernatants was analyzed by ELISA. Results are expressed as the mean \pm SD of 4 experiments. The dotted line represents the detection limit of ELISA. ${ }^{*} \mathrm{p}<0.05$ vs. vehicle. b Purified day- 4 BM-
DCs were treated with dimaprit (H2R agonist), $\mathrm{R}-\alpha$-methylhistamine (H3R agonist) or 4-methylhistamine (H4R agonist) at various concentrations as described in figure 1 . After $24 \mathrm{~h}$, TNF- $\alpha$ was assessed by ELISA. Results are shown as relative expression (\%) compared to control (mean \pm SD of 3 experiments). ${ }^{*} \mathrm{p}<0.05$ vs. control. 


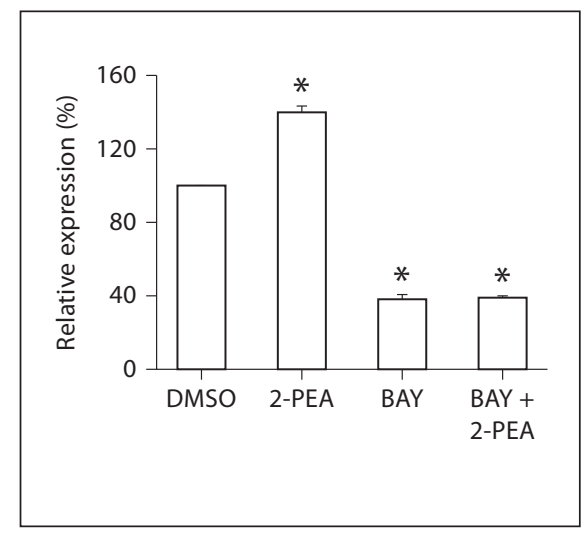

Fig. 3. NF- $\kappa \mathrm{B}$ inhibitor suppressed the basal level and H1R-agonist-induced TNF- $\alpha$ expression. Purified day-4 BM-DCs were treated with specific H1R agonist, 2-PEA $(10 \mu \mathrm{M})$ and/or NF- $\mathrm{B}$ inhibitor, BAY7085 (5 $\mu \mathrm{M})$, for $24 \mathrm{~h}$. The supernatant was collected for TNF- $\alpha$ determination using ELISA. Data are shown as relative expression (\%) compared to vehicle-treated cells (mean \pm SD of 2 experiments). The mean TNF- $\alpha$ level of vehicle-treated BM-DCs was $396 \mathrm{pg} / \mathrm{ml} .{ }^{*} \mathrm{p}<0.05$ vs. vehicle control.

$N F-\kappa B$ Involvement in the Downstream Signaling of $H 1 R$ on $B M-D C s$

As the expression of TNF- $\alpha /$ IL- 6 genes is regulated by the NF- $\kappa \mathrm{B}$ pathway, the NF- $\kappa \mathrm{B}$ pathway may be involved in the downstream signaling of H1R on BM-DCs. As shown in figure 3, 2-PEA, a highly selective H1R agonist [29], was able to increase the expression of TNF- $\alpha$; however, BAY7085, an NF-кB inhibitor, significantly inhibited basal and 2-PEA-induced TNF- $\alpha$ expression. Then LPS or poly I:C was used to activate the NF- $\mathrm{\kappa B}$ pathway [30] to examine whether TLR-mediated signaling interrupts or alleviates the effect of ketotifen on BM-DCs. As expected, ketotifen did not effectively inhibit TNF- $\alpha$ (fig. 4 ) and IL- 6 (data not shown) expression when BM-DCs were simultaneously treated with TLR agonist, LPS or poly I:C. These data suggest that NF- $\mathrm{KB}$ molecules are involved in the downstream signaling of H1R on BM-DCs.

\section{Effect of Blockage of H1R-Mediated Signaling on the Maturation and T-Cell Stimulatory Activity of $B M-D C s$}

Next, we examined whether H1R-mediated signaling is associated with the maturation and T-cell-stimulatory activity of BM-DCs. We analyzed the expression levels of MHC class II, CD80, CD86 and CD40 after treatment of day-4 BM-DCs with ketotifen in the presence of LPS or

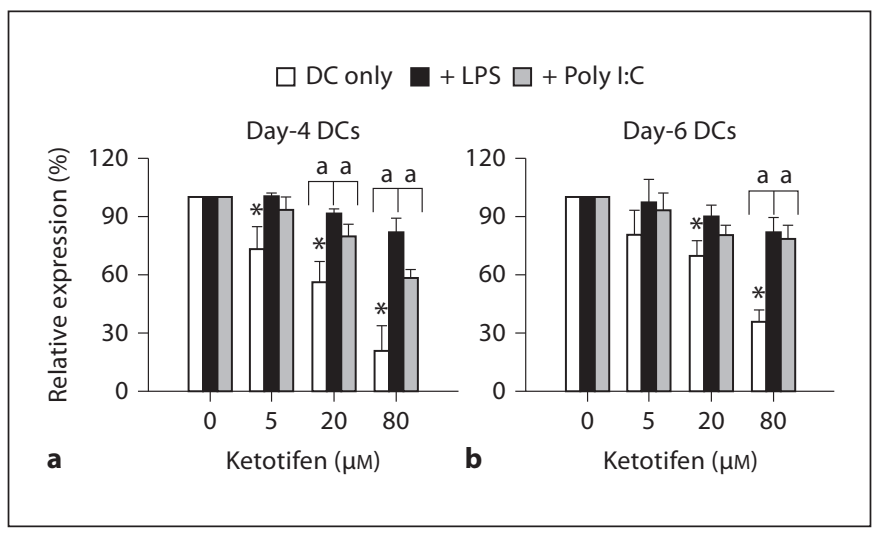

Fig. 4. LPS and poly I:C inhibited the effect of ketotifen on TNF- $\alpha$ production of BM-DCs. Purified day-4 (a) or -6 CD11c+ BM-DCs (b) were treated with different concentrations of ketotifen with LPS $(10 \mathrm{ng} / \mathrm{ml})$ or poly I:C $(10 \mu \mathrm{g} / \mathrm{ml})$ simultaneously for $24 \mathrm{~h}$. TNF- $\alpha$ levels in the culture supernatants were determined by multiplex immunoassay. Results are shown as relative expression (\%) compared to untreated DCs, or DCs stimulated with LPS or poly I:C (mean $\pm \mathrm{SD}$ of 3 experiments). ${ }^{*} \mathrm{p}<0.05$ vs. BM-DCs without ketotifen. ${ }^{a} \mathrm{p}<0.05$ vs. BM-DCs with ketotifen.

poly I:C. As shown in figure 5, LPS and poly I:C markedly increased the percentages of MHC class $\mathrm{II}^{\text {high }}$, CD80+, CD86+ and CD40+ in CD11c+ BM-DCs. However, compared with vehicle-treated cells (gray areas in fig. 5), ketotifen did not change the expression levels and percentages of these molecules on CD11c+ BM-DCs (solid lines in fig. 5) either under TLR agonist-stimulated or non-stimulated conditions. Ketotifen did not have a significant effect on the maturation of day-6 BM-DCs either (data not shown). We then further examined the T-cellstimulatory activity of treated BM-DCs; there was no significant difference in the DO11.10 CD4+ T-cell proliferative response elicited by ketotifen-treated BM-DCs compared with control cells (data not shown). These data demonstrate that H1R-mediated signaling regulates the expression of proinflammatory cytokines on BM-DCs, but not their maturation and T-cell stimulatory activity.

\section{Effect of c-Rel, the Downstream Element of \\ $H 1 R-M e d i a t e d$ Signaling, on TNF- $\alpha$ Expression of $B M-D C s$}

In order to examine whether NF- $\mathrm{BB}$ activity is involved in the downstream signaling of H1R on BM-DCs, an NF- $\kappa$ B luciferase reporter gene assay was performed to examine whether blocking H1R-mediated signaling could affect NF- $\kappa$ B activity. As shown in figure 6 , ketoti- 


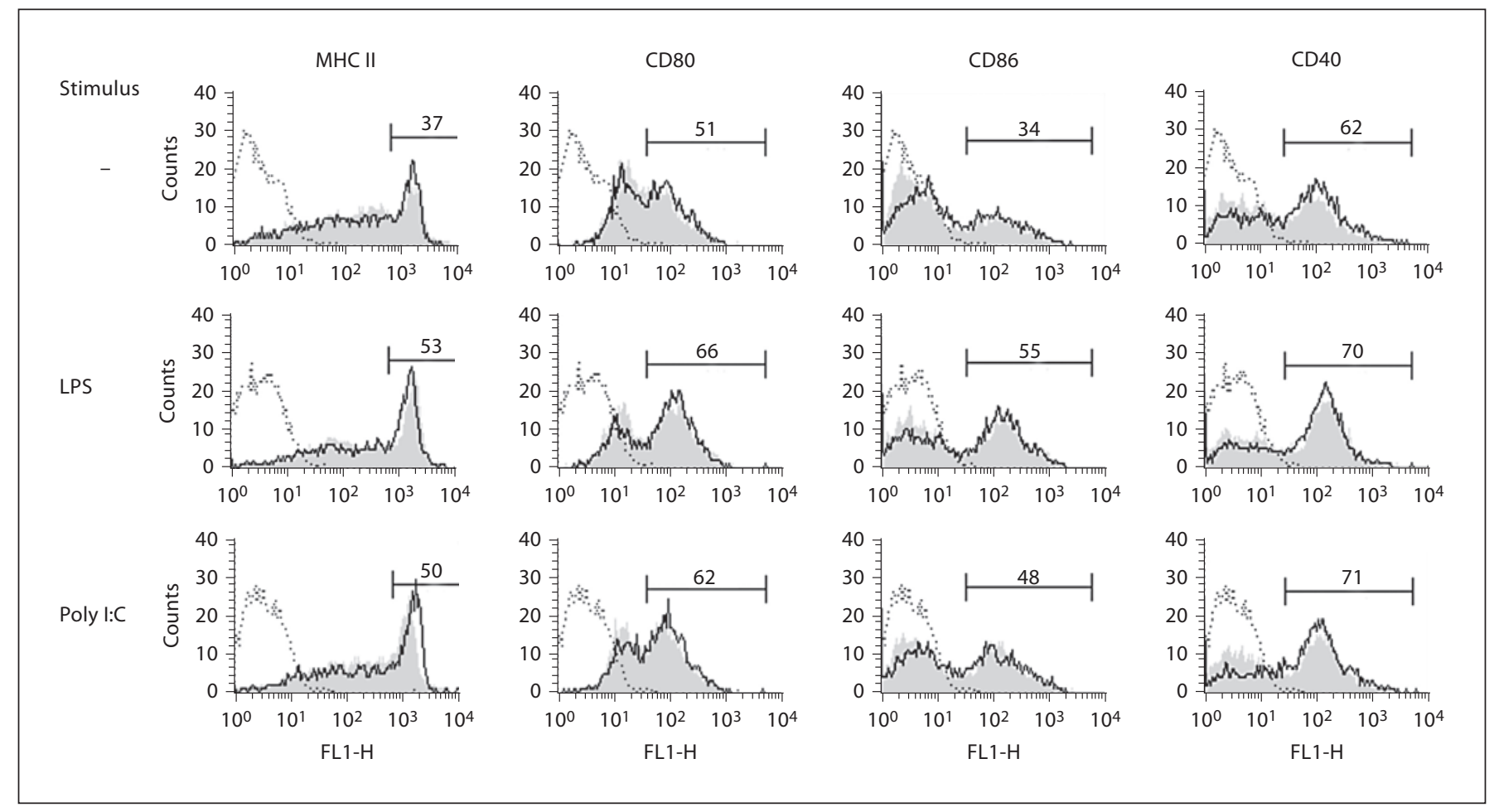

Fig. 5. Ketotifen did not affect the maturity of BM-DCs. Day-4 BM-DCs were treated with ketotifen $(80 \mu \mathrm{M})$ concomitant with LPS $(10 \mathrm{ng} / \mathrm{ml})$ or poly I:C $(10 \mu \mathrm{g} / \mathrm{ml})$ for $24 \mathrm{~h}$. The harvested cells were stained with fluorochrome-labeled antibodies for CD11c, CD40, CD80, CD86 and MHC class II and analyzed by

fen significantly inhibited basal NF- $\mathrm{kB}$ activity of THP-1 cells in a dose-dependent manner. Next, we examined which subunit(s) of NF- $\kappa \mathrm{B}$ regulated TNF- $\alpha$ expression during H1R-mediated signaling of BM-DCs. We analyzed the expression levels of all subunits of NF- $\kappa$ B in ketotifen-treated BM-DCs. As shown in figure 7a, nontreated BM-DCs expressed basal levels of most of the NF$\kappa \mathrm{B}$ subunits except $\mathrm{p} 52$. We found that ketotifen significantly decreased c-Rel expression of BM-DCs (fig. 7b). Although high-dose ketotifen seemed to inhibit p50 expression of BM-DCs (fig. 7a), this inhibition was not consistently observed in different independent experiments.

To further examine whether c-Rel directly regulated TNF- $\alpha$ expression during H1R-mediated signaling of BMDCs, we investigated the binding of $c$-Rel to the promoter region in the TNF- $\alpha$ gene in day- 4 BM-DCs treated with or without ketotifen. As shown in figure 7c, chromatin immunoprecipitation showed that ketotifen significantly decreased the binding of $\mathrm{c}$-Rel to the $\kappa \mathrm{B}$ site of TNF- $\alpha$ promoter. These data revealed that the interaction between flow cytometry. The histograms shown were gated for live, CD11c+ cells. Percentages of gated cells from ketotifen-treated cells are shown in each graph. Data are representative of 3 experiments. Dotted line = Isotype control; gray area = vehicle; solid line $=$ ketotifen.

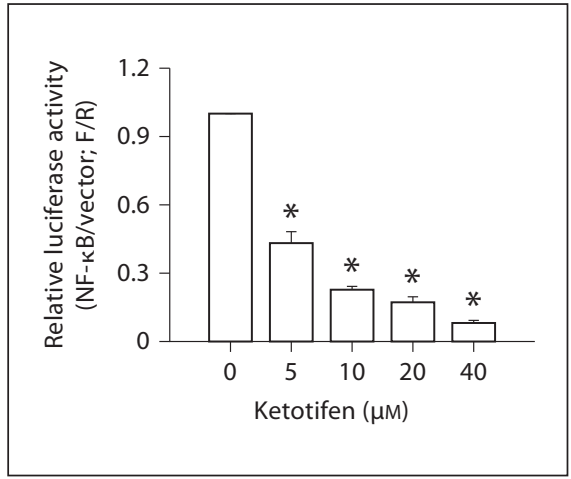

Fig. 6. Ketotifen suppressed cellular NF- $\kappa \mathrm{B}$ transactivity in THP1 cells. pRL-SV40 reporter (Renilla luciferase; R) was cotransfected with pNF- $\kappa$ BLuc reporter or control vector (firefly luciferase; F) into THP-1 cells. After ketotifen treatment, relative luciferase activity was defined as firefly/Renilla ratio, normalized to control vector transfection. The results are shown as means \pm SD of quadruplicate experiments. ${ }^{*} \mathrm{p}<0.05$ vs. vehicle control. 


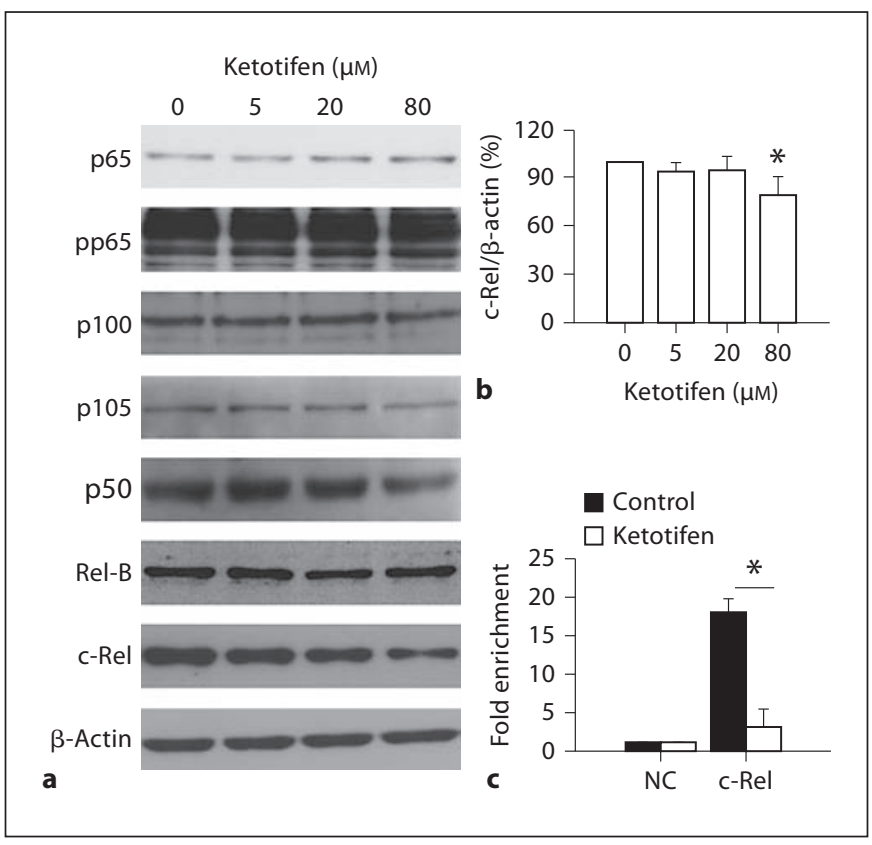

Fig. 7. Ketotifen inhibited c-Rel expression and its binding to the $\kappa \mathrm{B}$ site of the TNF- $\alpha$ promoter in BM-DCs. a Western blotting was performed to examine the expression of NF- $\kappa \mathrm{B}$ subunits and $\beta$-actin in day-4 BM-DCs treated with the indicated concentrations of ketotifen for $2 \mathrm{~h}$. Data are representative of 3 experiments. b Results are shown as relative ratios (\%) of c-Rel vs. $\beta$-actin (mean \pm SE of 3 independent experiments). c Day-4 BM-DCs were treated with or without ketotifen $(80 \mu \mathrm{M})$ for $2 \mathrm{~h}$ before formaldehyde fixation. Soluble, fragmented chromatin was immunoprecipitated with antibody specific for c-Rel. Negative control (NC) was performed without anti-c-Rel antibody. DNA was quantified by real-time PCR using primers specific for the $\kappa B$ binding site of the mouse TNF- $\alpha$ promoter. The fold enrichment values for c-Rel binding were determined by normalizing to noantibody signals (NC). Results are shown as fold enrichment (mean $\pm \mathrm{SD}$ of 3 experiments).

c-Rel and the TNF- $\alpha$ promoter was downregulated in ketotifen-treated BM-DCs compared with untreated cells. Therefore, H1R-mediated signaling may activate c-Rel to directly regulate TNF- $\alpha$ expression of BM-DCs.

Effect of Blockage of H1R-Mediated Signaling in DCs on OVA-Induced Allergic Lung Inflammation in vivo

To test the functional consequences of H1R-mediated signaling interruption in DCs in vivo, we examined the effect of the transfer of ketotifen-treated OVA-pulsed BM-DCs into naïve BALB/c mice before OVA challenge. Wild-type recipients of vehicle-treated OVA/BM-DCs significantly developed airway eosinophilia (fig. 8a) and increased Th2 cytokine expression (fig. 8b). This was in contrast to the response following the transfer of ketotifen-treated OVA/BM-DCs, where neither airway eosinophilia nor allergic cytokine responses developed. Therefore, blockage of H1R-mediated signaling in local DCs may alleviate allergic responses.

\section{Discussion}

Histamine can significantly enhance the inflammatory activity of DCs through H1R. Although previous studies suggested that NF- $\kappa \mathrm{B}$ family transcription factors are involved in the downstream signaling of $\mathrm{H} 1 \mathrm{R}$, which NF- $\kappa \mathrm{B}$ family members are required and whether they directly regulate the inflammatory genes remains unclear. This is, to our knowledge, the first report to demonstrate that c-Rel directly controls TNF- $\alpha$ expression in H1R-mediated signaling in DCs. Also, our study demonstrates that the basal proinflammatory activity of DCs is, at least in part, associated with H1R-mediated NF- $\mathrm{BB}$ еxpression. In addition, blockage of H1R-mediated signaling may reduce allergic responses in vivo. This study provides a molecular basis in the H1R-c-Rel-TNF- $\alpha$ axis for controlling allergic inflammation.

DCs express almost all NF- $\mathrm{B}$ subunits, suggesting the importance of distinct subunit composition in DC differentiation and function. It has been reported that deficiency in p50/c-Rel or c-Rel alone does not affect DC development, but rather perturbs the maturation and survival of DCs [11]. In contrast, RelB-knockout mice exhibit defective myeloid DC differentiation [31]. Furthermore, it has been demonstrated that c-Rel is the specific transcriptional regulator of both IL-12/p35 [32] and IL23/p19 [33] gene expression in DCs. Using a knockout system, it has been shown that c-Rel also positively regulates TNF- $\alpha$ expression in macrophages [34]. Our study here shows that c-Rel directly binds to the TNF- $\alpha$ promoter and regulates its basal expression under H1R-mediated signaling in DCs. It also implies that c-Rel may form homodimers to regulate TNF- $\alpha$ expression as interruption of H1R signaling specifically impacts only c-Rel expression (fig. 7a). Taken together, these findings suggest that c-Rel is responsible for DC costimulatory function, such as TNF- $\alpha$ and IL-12 production. The detailed regulatory mechanisms in the H1R-c-Rel-TNF- $\alpha$ axis still need to be further elucidated.

It has been shown that H1R-/- BM-DCs display an immature phenotype, secrete a modified cytokine pattern and alter T-cell polarization [35]. However, in our study, blockage of H1R signaling primarily affects the 
Fig. 8. Administration of OVA/BM-DCs treated with ketotifen induced less severe lung allergic responses than control. Purified day-4 BM-DCs were treated with ketotifen (K) or vehicle (NC) in the presence of OVA for $24 \mathrm{~h}$ before transfer into naïve $\mathrm{BALB} / \mathrm{c}$ mice. Seven days later, mice received 4 daily OVA aerosol challenges. Cellular composition (a) and cytokine pattern (b) of BALF were analyzed using flow cytometry and ELISA, respectively. $\mathrm{n}=$ 4-5 mice/group. Data are representative of 2 experiments. The line within the vertical points marks the mean for each group. ${ }^{*} \mathrm{p}<0.05$ vs. NC.

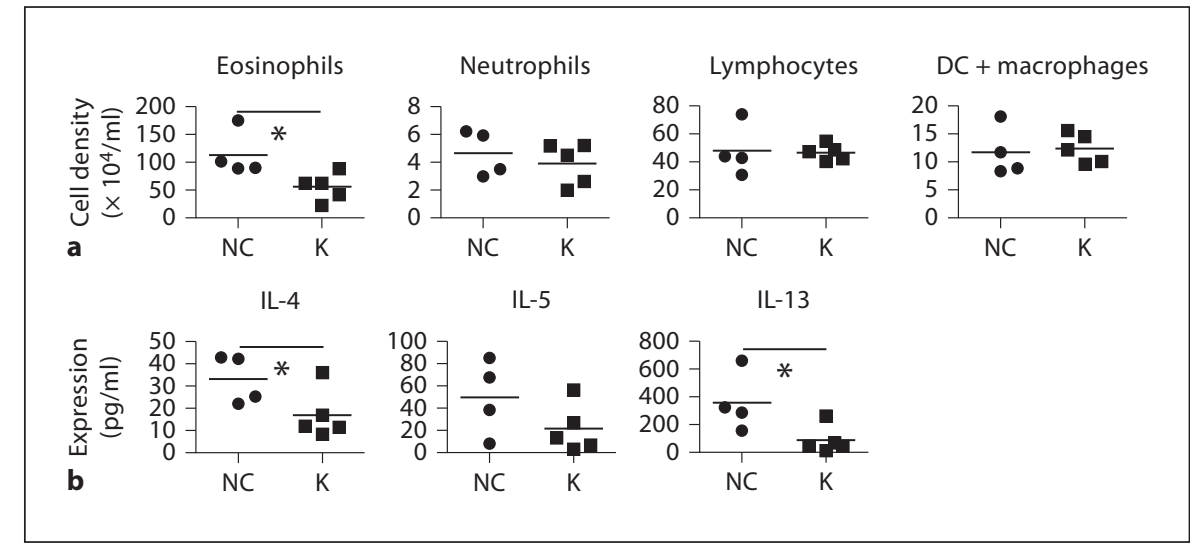

proinflammatory activity but not the maturation or Tcell-stimulatory activity in the well-differentiated BMDCs. On the other hand, in the context of allergic inflammation, histamine exerts its effect on differentiated DCs not only through H1R and H2R, but also through the recently identified H4R $[4,15,16]$. Taken together, H1R signaling mediated by histamine affects the regulation of both DC differentiation and function.

The molecular mechanisms involved in the basal proinflammatory activity of DCs are still unknown. This activity is, at least in part, associated with constitutive NF- $\kappa$ B expression (fig. 7a). We suggest that the basal proinflammatory activity of DCs may be associated with constitutive H1R-mediated NF- $\kappa \mathrm{B}$ activation for the following reasons. First, DCs can express at least three types of HR. Just like other G-protein-coupled receptors, HRs demonstrate an equilibrium between their active and inactive states [5]. Constitute HR activity exists and is independent of receptor occupancy by an agonist in cell line context [19]. Second, DCs can actively synthesize endogenous histamine in autocrine and paracrine ways [18]. Third, it has also been demonstrated that H1R activates $\mathrm{NF}-\kappa \mathrm{B}$ in both a constitutive and agonist-dependent manner in cell line experiments [6]. Finally, as shown in our study, H1R-mediated signaling leads to TNF- $\alpha$ expression through $c$-Rel activity, and then TNF- $\alpha$ may further activate the downstream NF- $\kappa \mathrm{B}$ pathway. This may be the reason why an H1R-specific agonist (2-PEA) increased basal TNF- $\alpha$ expression about 1.5-fold, but NF- $\kappa B$ inhibitor (BAY7085) significantly suppressed the TNF- $\alpha$ level to $30 \%$ of control (fig. 3). Understanding the detailed molecular mechanisms involved in H1R-mediated proinflammatory activity may have a great impact on the development of therapeutic targets for the treatment of DC-mediated inflammatory diseases.
In diseases characterized by allergic inflammation, such as asthma, DCs are essential for Th2-mediated airway inflammation [36]. It has been shown that the number of airway DCs increases 80 -fold in experimental asthma [37]. Also, increased NF- $\kappa$ B activity and TNF- $\alpha$ levels have been demonstrated in the airways in human and animal models of asthma [38]. Combined with our data, this implies that in the context of chronic inflammation, increases in DCs result in increased TNF- $\alpha$ secretion due to the constitutive H1R activity even in the absence of histamine in the microenvironment. As TNF- $\alpha$ has many pleiotropic activities and plays an important role in the pathogenesis of allergic diseases [39], strategies targeting the H1R-c-Rel-TNF- $\alpha$ axis in DCs may provide a novel alternative for controlling allergic inflammation.

Our results clearly show that H1R-mediated signaling in DCs controls TNF- $\alpha$ expression through c-Rel activity. This study provides a potential basis for clarifying the crosstalk between H1R and NF- $\kappa \mathrm{B}$ pathways and for designing treatments affecting the H1R-c-Rel-TNF- $\alpha$ axis to control allergic inflammation.

\section{Acknowledgments}

We thank Dr. Shau-Ku Huang for helpful advice and careful review of the study. This work was supported by grants from National Health Research Institutes (NHRI-EX101-9824SC). We thank the Center for Resources, Research and Development of KMU for providing LSRII.

\section{Disclosure Statement}

The authors declare that they have no competing interests. 


\section{References}

1 Thurmond RL, Gelfand EW, Dunford PJ: The role of histamine $\mathrm{H} 1$ and $\mathrm{H} 4$ receptors in allergic inflammation: the search for new antihistamines. Nat Rev Drug Discov 2008; 7:41-53.

-2 Teuscher C, Subramanian M, Noubade R, Gao JF, Offner H, Zachary JF, et al: Central histamine $\mathrm{H} 3$ receptor signaling negatively regulates susceptibility to autoimmune inflammatory disease of the CNS. Proc Natl Acad Sci USA 2007;104:10146-10151.

>3 Thurmond RL, Desai PJ, Dunford PJ, FungLeung WP, Hofstra CL, Jiang W, et al: A potent and selective histamine $\mathrm{H} 4$ receptor antagonist with anti-inflammatory properties. J Pharmacol Exp Ther 2004;309:404-413.

-4 Dunford PJ, O’Donnell N, Riley JP, Williams KN, Karlsson L, Thurmond RL: The histamine $\mathrm{H} 4$ receptor mediates allergic airway inflammation by regulating the activation of CD4+ T cells. J Immunol 2006;176:7062-7070.

5 Akdis CA, Simons FE: Histamine receptors are hot in immunopharmacology. Eur J Pharmacol 2006;533:69-76.

-6 Bakker RA, Schoonus SB, Smit MJ, Timmerman H, Leurs R: Histamine H(1)-receptor activation of nuclear factor-kappa B: roles for $\mathrm{G}$ beta gamma- and $\mathrm{G}$ alpha(q/11)-subunits in constitutive and agonist-mediated signaling. Mol Pharmacol 2001;60:1133-1142.

>7 Matsubara M, Tamura T, Ohmori K, Hasegawa $\mathrm{K}$ : Histamine $\mathrm{H} 1$ receptor antagonist blocks histamine-induced proinflammatory cytokine production through inhibition of Ca2+-dependent protein kinase C, Raf/ MEK/ERK and IKK/I kappa B/NF-kappa B signal cascades. Biochem Pharmacol 2005; 69:433-449.

8 Amsen D, Blander JM, Lee GR, Tanigaki K, Honjo T, Flavell RA: Instruction of distinct CD4 T helper cell fates by different notch ligands on antigen-presenting cells. Cell 2004; 117:515-526.

9 Hammad H, Lambrecht BN: Dendritic cells and epithelial cells: linking innate and adaptive immunity in asthma. Nat Rev Immunol 2008;8:193-204.

-10 Manzouri B, Flynn T, Ohbayashi M, Ono SJ: The dendritic cell in allergic conjunctivitis. Ocul Surf 2008;6:70-78.

-11 Ouaaz F, Arron J, Zheng Y, Choi Y, Beg AA: Dendritic cell development and survival require distinct NF-kappaB subunits. Immunity $2002 ; 16: 257-270$.

12 Wang J, Wang X, Hussain S, Zheng Y, Sanjabi S, Ouaaz F, et al: Distinct roles of different NF-kappa B subunits in regulating inflammatory and $\mathrm{T}$ cell stimulatory gene expression in dendritic cells. J Immunol 2007; 178:6777-6788

13 Tak PP, Firestein GS: NF-kappaB: a key role in inflammatory diseases. J Clin Invest 2001; 107:7-11.

14 Idzko M, la Sala A, Ferrari D, Panther E, Herouy Y, Dichmann S, et al: Expression and function of histamine receptors in human monocyte-derived dendritic cells. J Allergy Clin Immunol 2002;109:839-846.

-15 Mazzoni A, Young HA, Spitzer JH, Visintin A, Segal DM: Histamine regulates cytokine production in maturing dendritic cells, resulting in altered $\mathrm{T}$ cell polarization. J Clin Invest 2001;108:1865-1873.

16 Caron G, Delneste Y, Roelandts E, Duez C, Bonnefoy JY, Pestel J, et al: Histamine polarizes human dendritic cells into Th2 cell-promoting effector dendritic cells. J Immunol 2001;167:3682-3686.

17 Jutel M, Watanabe T, Klunker S, Akdis M, Thomet OA, Malolepszy J, et al: Histamine regulates $\mathrm{T}$-cell and antibody responses by differential expression of $\mathrm{H} 1$ and $\mathrm{H} 2$ receptors. Nature 2001;413:420-425.

18 Szeberenyi JB, Pallinger E, Zsinko M, Pos Z, Rothe G, Orso E, et al: Inhibition of effects of endogenously synthesized histamine disturbs in vitro human dendritic cell differentiation. Immunol Lett 2001;76:175-182.

19 Leurs R, Church MK, Taglialatela M: H1-antihistamines: inverse agonism, anti-inflammatory actions and cardiac effects. Clin Exp Allergy 2002;32:489-498.

20 Inaba K, Inaba M, Romani N, Aya H, Deguchi M, Ikehara S, et al: Generation of large numbers of dendritic cells from mouse bone marrow cultures supplemented with granulocyte/macrophage colony-stimulating factor. J Exp Med 1992;176:1693-1702.

21 Suen JL, Chuang YH, Tsai BY, Yau PM, Chiang BL: Treatment of murine lupus using nucleosomal $\mathrm{T}$ cell epitopes identified by bone marrow-derived dendritic cells. Arthritis Rheum 2004;50:3250-3259.

22 Suen JL, Liu CC, Lin YS, Tsai YF, Juo SH, Chou YH: Urinary chemokines/cytokines are elevated in patients with urolithiasis. Urol Res 2010;38:81-87.

23 van Rijt LS, Kuipers H, Vos N, Hijdra D, Hoogsteden HC, Lambrecht BN: A rapid flow cytometric method for determining the cellular composition of bronchoalveolar lavage fluid cells in mouse models of asthma. J Immunol Methods 2004;288:111-121.

-24 Abelson MB, Ferzola NJ, McWhirter CL, Crampton HJ: Efficacy and safety of singleand multiple-dose ketotifen fumarate $0.025 \%$ ophthalmic solution in a pediatric population. Pediatr Allergy Immunol 2004; 15:551-557.

25 Kabra SK, Pandey RM, Singh R, Seth V: Ketotifen for asthma in children aged 5 to 15 years: a randomized placebo-controlled trial. Ann Allergy Asthma Immunol 2000;85: 46-52.

26 Wu KG, Li TH, Wang TY, Hsu CL, Chen CJ: A comparative study of loratadine syrup and cyproheptadine $\mathrm{HCl}$ solution for treating perennial allergic rhinitis in Taiwanese children aged 2-12 years. Int J Immunopathol Pharmacol 2012;25:231-237.
27 Son YI, Egawa S, Tatsumi T, Redlinger RE Jr, Kalinski P, Kanto T: A novel bulk-culture method for generating mature dendritic cells from mouse bone marrow cells. J Immunol Methods 2002;262:145-157.

-28 Amaral MM, Davio C, Ceballos A, Salamone G, Canones C, Geffner J, et al: Histamine improves antigen uptake and cross-presentation by dendritic cells. J Immunol 2007;179: 3425-3433.

29 Durant GJ, Ganellin CR, Parsons ME: Chemical differentiation of histamine $\mathrm{H} 1-$ and H2-receptor agonists. J Med Chem 1975; 18:905-909.

30 Kawai T, Akira S: The role of pattern-recognition receptors in innate immunity: update on Toll-like receptors. Nat Immunol 2010;11: 373-384.

31 Wu L, D’Amico A, Winkel KD, Suter M, Lo $\mathrm{D}$, Shortman K: RelB is essential for the development of myeloid-related CD8alphadendritic cells but not of lymphoid-related CD8alpha+ dendritic cells. Immunity 1998; 9:839-847.

32 Grumont R, Hochrein H, O'Keeffe M, Gugasyan R, White C, Caminschi I, et al: c-Rel regulates interleukin 12 p70 expression in CD8(+) dendritic cells by specifically inducing p35 gene transcription. J Exp Med 2001; 194:1021-1032.

33 Carmody RJ, Ruan Q, Liou HC, Chen YH Essential roles of c-Rel in TLR-induced IL-23 p19 gene expression in dendritic cells. J Immunol 2007;178:186-191.

34 Grigoriadis G, Zhan Y, Grumont RJ, Metcalf D, Handman E, Cheers C, et al: The Rel subunit of NF-kappaB-like transcription factors is a positive and negative regulator of macrophage gene expression: distinct roles for Rel in different macrophage populations. EMBO J 1996;15:7099-7107.

35 Vanbervliet B, Akdis M, Vocanson M, Rozieres A, Benetiere J, Rouzaire P, et al: Histamine receptor $\mathrm{H} 1$ signaling on dendritic cells plays a key role in the IFN-gamma/IL17 balance in T cell-mediated skin inflammation. J Allergy Clin Immunol 2011;127: 943-953.e1-e10.

36 Lambrecht BN, Hammad H: Taking our breath away: dendritic cells in the pathogenesis of asthma. Nat Rev Immunol 2003;3: 994-1003.

-37 Vermaelen K, Pauwels R: Accelerated airway dendritic cell maturation, trafficking, and elimination in a mouse model of asthma. Am J Respir Cell Mol Biol 2003;29:405-409.

38 Bureau F, Delhalle S, Bonizzi G, Fievez L, Dogne S, Kirschvink N, et al: Mechanisms of persistent NF-kappa B activity in the bronchi of an animal model of asthma. J Immunol 2000;165:5822-5830.

39 Berry MA, Hargadon B, Shelley M, Parker D, Shaw DE, Green RH, et al: Evidence of a role of tumor necrosis factor alpha in refractory asthma. N Engl J Med 2006;354:697-708. 